\title{
Assessment of expected breeding values for fertility traits of Murrah buffaloes under subtropical climate
}

\author{
Soumya Dash ${ }^{1}$, A. K. Chakravarty ${ }^{1}$, Avtar Singh ${ }^{1}$, Pushp Raj Shivahre ${ }^{1}$, Arpan Upadhyay ${ }^{1}$, Vaishali Sah ${ }^{2}$ \\ and K. Mahesh Singh ${ }^{1}$
}

\begin{abstract}
1. Dairy Cattle Breeding Division, National Dairy Research Institute, Karnal, Haryana, India; 2. Division of Animal Genetics, Indian Veterinary Research Institute, Izatnagar, Bareilly, Uttar Pradesh, India.

Corresponding author: Soumya Dash, e-mail: dr.soumya10@gmail.com,
\end{abstract}

AKC: ak_chakravarty@yahoo.co.in, AS: avtar54@gmail.com, PRS: drpro6@gmail.com, AU: upadhyay.arpan@gmail.com, VS: vaishalisah.sah@gmail.com, KMS: maheshsngh7@gmail.com

Received: 14-10-2014, Revised: 25-01-2015, Accepted: 02-02-2015, Published online: 12-03-2015

doi: 10.14202/vetworld.2015.320-325. How to cite this article: Dash S, Chakravarty AK, Singh A, Shivahre PR, Upadhyay A, Sah V, Singh KM (2015) Assessment of expected breeding values for fertility traits of Murrah buffaloes under subtropical climate, Veterinary World 8(3):320-325.

\begin{abstract}
Aim: The aim of the present study was to assess the influence of temperature and humidity prevalent under subtropical climate on the breeding values for fertility traits viz. service period (SP), pregnancy rate (PR) and conception rate (CR) of Murrah buffaloes in National Dairy Research Institute (NDRI) herd.

Materials and Methods: Fertility data on 1379 records of 581 Murrah buffaloes spread over four lactations and climatic parameters viz. dry bulb temperature and relative humidity (RH) spanned over 20 years (1993-2012) were collected from NDRI and Central Soil and Salinity Research Institute, Karnal, India. Monthly average temperature humidity index (THI) values were estimated. Threshold THI value affecting fertility traits was identified by fixed least-squares model analysis. Three zones of non-heat stress, heat stress and critical heat stress zones were developed in a year. The genetic parameters heritability $\left(\mathrm{h}^{2}\right)$ and repeatability (r) of each fertility trait were estimated. Genetic evaluation of Murrah buffaloes was performed in each zone with respect to their expected breeding values (EBV) for fertility traits.

Results: Effect of THI was found significant $(\mathrm{p}<0.001)$ on all fertility traits with threshold THI value identified as 75 . Based on THI values, a year was classified into three zones: Non heat stress zone(THI 56.71-73.21), HSZ (THI 75.39-81.60) and critical HSZ (THI 80.27-81.60). The EBVfor SP, PR, CR were estimated as 138.57 days, 0.362 and $69.02 \%$ in non-HSZ while in HSZ EBV were found as 139.62 days, 0.358 and $68.81 \%$, respectively. EBV for SP was increased to 140.92 days and for PR and CR, it was declined to 0.357 and $68.71 \%$ in critical HSZ.
\end{abstract}

Conclusion: The negative effect of THI was observed on EBV of fertility traits under the non-HSZ and critical HSZ Thus, the influence of THI should be adjusted before estimating the breeding values for fertility traits in Murrah buffaloes.

Keywords: critical heat stress zone, expected breeding value, murrah buffaloes, temperature humidity index.

\section{Introduction}

India is the largest producer of milk in the world and buffaloes contribute the highest (56.64\%) share to milk production [1]. According to $19^{\text {th }}$ livestock census [2], the population of buffaloes are quite uprising, and there are 108.7 million numbers of buffaloes present in India. Buffaloes are considered as a triple purpose species producing milk, meat and draft power for agriculture work. One of the most limiting factors in dairy production in the subtropical climate is heat stress. Heat stress is defined as the combination of environmental parameters producing conditions that are higher than the temperature range of animal's thermal neutral zone [3]. Buffaloes are highly susceptible to heat stress, especially under direct exposure to the sun's rays since its evaporative cutaneous cooling mechanism is weak due to the presence of low density of sweat glands [4]. Heat stress causes summer anoestrous which hinders the reproductive efficiency

Copyright: The authors. This article is an open access article licensed under the terms of the Creative Commons Attributin License (http:// creative commons.org/licenses/by/2.0) which permits unrestricted use, distribution and reproduction in any medium, provided the work is properly cited. in buffaloes [5]. The effect of heat stress is aggravated when heat stress is accompanied by high ambient humidity [6]. Buffaloes are considered as seasonal breeders, since most of the buffaloes come into oestrus during winter, and a very less number show oestrus in summer. Of late, it has been observed that heat stress can be more accurately quantified by temperature humidity index (THI) which takes into account the combined effect of air temperature and relative humidity (RH). When the mean THI was more than 80 , there was a significant decrease in conception rate $(\mathrm{CR})$ of lactating dairy cows [7]. Ravagnolo and Misztal [8] found a decrease in non-return rate (NR45) of 0.005 with per unit increase in THI above 68 on the day of service in Holstein cows. Variance of heat stress was found zero at THI 70 but it was started to increase with increase in THI and become equal to additive genetic variance at THI 84 for NR90 that indicated the presence of genetic variation in heat tolerance at high level of THI among Holstein cows. Phenotypic expression of any trait depends on both genotype and environment. Breeding value is twice the average deviation of its offspring from the population mean. 
The estimation of expected breeding value for the traits defines the total genetic worth of the individual. The prediction of breeding values constitutes an integral part of most breeding programmes for genetic improvement of economic traits of Murrah buffaloes. The accuracy of estimating the breeding value of an animal is a major concern affecting the genetic progress due to selection [9]. The estimated breeding values for pregnancy rate (PR) of Angus heifers ranged from -0.02 to 0.05 [10].

The hypothesis of the study was to assess the role of environment, as well as genotype on the fertility traits of Murrah buffaloes. Until today, there is no report available on the assessment of EBV s for fertility traits of Murrah buffaloes under the non-heat stress, heat stress and critical heat stress zones (CHSZ) of a year. This investigation, therefore, is aimed to find out the expected breeding values (EBV) of fertility traits in three different defined zones of a year.

\section{Materials and Methods \\ Ethical approval}

This study is based on animal breeding data and it does not include animal experiment. So the ethical approval was not required.

\section{Herd location and general management}

The present study was conducted on Murrah buffaloes maintained at Livestock Research Centre, National Dairy Research Institute (NDRI), Karnal, Haryana, India, located at $29^{\circ} 42^{\circ} \mathrm{N}$ latitude and $72^{\circ}$ $02^{\prime}$ E longitudes in the bed of Indo-Gangetic alluvial plain. The climate of Karnal is subtropical in nature. There are four major seasons in the year viz. winter (December-March), summer (April-June), rainy (JulySeptember) and autumn (October and November). The average temperatures in the four seasons were $15.6^{\circ} \mathrm{C}, 35.8^{\circ} \mathrm{C}, 28.7^{\circ} \mathrm{C}$ and $22.5^{\circ} \mathrm{C}$ and the average RH were $71.34 \%, 48 \%, 79 \%$ and $65 \%$, respectively. Buffaloes were maintained in a loose housing system with brick on edges flooring under group management practice. The nutritional requirements of buffaloes were fulfilled through a standardized balanced ration of seasonal green fodders along with concentrates. Oestrus detection was carried out with the help of teaser Murrah bull (vasectomised bulls). Females detected in oestrus were inseminated with frozen semen of progeny tested bulls and pregnancy was confirmed after 45 days of insemination through rectal palpation as per standard management practices of the herd. Only healthy buffaloes were included while abortion, metritis, still birth, retained placenta and dystocia records were considered abnormal, and these were not included in the present study.

\section{Fertility data}

The information related to fertility of Murrah buffaloes was collected from records maintained by dairy cattle breeding division, NDRI, Karnal. A total of 1379 records of 581 Murrah buffaloes under $1^{\text {st }}, 2^{\text {nd }}, 3^{\text {rd }}$ and $4^{\text {th }}$ parity spanned over a period of 20 years from July 1993 to December 2012 were collected. Three traits were generated such as service period (SP), PR and $\mathrm{CR}$. The SP of buffaloes with more than 350 days was excluded from the study. The data were normalized with mean \pm 3 standard deviation (SD) for SP. PR is a new and recent method of measuring fertility in buffaloes. It is defined as the percentage of non-pregnant buffaloes to become pregnant during each 21 days after voluntary waiting period (VWP)[11].

$\mathrm{PR}=21 /(\mathrm{SP}-\mathrm{VWP}+11)$

Where, VWP is the days in milk when buffaloes were not inseminated and VWP of Murrah Buffaloes has been standardized as 63 days at NDRI herd [12]. The CR of Murrah Buffaloes was computed with the following formula: $\mathrm{CR}=1 / \mathrm{N} * 100$

Where, $\mathrm{N}=$ No. of inseminations required for pregnancy. A summary of the edited and normalized data sets is presented in Table-1.

\section{Weather data and estimation of THI}

Meteorological data pertaining to daily dry bulb temperature $\left(\mathrm{T}_{\mathrm{db}}\right)$ and RHwith the corresponding period of study were obtained from Central Soil and Salinity Research Institute, Karnal. Monthly average $\mathrm{T}_{\mathrm{db}}\left({ }^{\circ} \mathrm{C}\right)$ and $\mathrm{RH}(\%)$ were computed from daily weather information and subsequently the information were used to calculate the monthly average dewpoint temperature $\left(\mathrm{T}_{\mathrm{dp}}\right)$ by the method given by Jensen et al. [13]. $\mathrm{T}_{\mathrm{dp}}=116.9+237.3 \times \ln (\mathrm{e}) / 16.78-\ln (\mathrm{e})$, where, $\mathrm{e}(\mathrm{Kpa})=$ ambient vapour pressure.

$$
\left(\mathrm{e}(\mathrm{kPa})=\frac{\mathrm{rh} \times 0.611 \times \mathrm{e}^{\left(\frac{17.27 \times \mathrm{Tdb}}{\mathrm{Tdb}+237.3}\right)}}{100}\right)
$$

THI values were estimated on a monthly basis from January to December for each of 20 years (19932012) by using the formula given by Yousef [14].

$$
\mathrm{THI}=\mathrm{T}_{\mathrm{db}}+\left(0.36 \times \mathrm{T}_{\mathrm{dp}}\right)+41.2
$$

\section{Statistical analysis}

The data were distributed up to fourth parity in the present study. A total of 13 periods of calving were taken with an interval of 18 months artificial insemination cycle of a set of Murrah bulls for each period according to progeny testing programme under network project on Buffalo improvement. Ages of Murrah buffaloes at first calving were classified into t 3 Groups i.e., age Group 1: < 37 months; Age Group 2: 37-53 months and age group 3: $>53$ months, using mean and one standard deviation in the population. The effect of non-genetic factors like parity, period of calving and age group at first calving on normalized traits viz; SP, PR and CR were assessed by using a fixed model least-squares analysis with least-squares maximum likelihood software (LSML) as suggested by Harvey [15]. The statistical model 
used was

$\mathrm{Y}_{\mathrm{ijk}}=\mu+\mathrm{pa}_{\mathrm{i}}+\mathrm{p}_{\mathrm{j}}+(\mathrm{AG})_{\mathrm{k}}+\mathrm{e}_{\mathrm{ijkl}}$

where, $\mathrm{Y}_{\mathrm{ijkl}}$ is the observation on $1^{\text {th }}$ Murrah buffalo belonging to $\mathrm{k}^{\text {th }}$ age group at first calving calved in $\mathrm{j}^{\text {th }}$ period of calving in $\mathrm{i}^{\text {th }}$ parity, and $\mathrm{e}_{\mathrm{ijkl}}$ is random error $\sim$ NID $\left(0, \sigma_{\mathrm{e}}^{2}\right)$. The analysis of variance for the non-genetic factors affecting different fertility traits was computed and the difference of means between significant sub-classes was tested by using Duncan's multiple range test (DMRT) as modified by Kramer [16]. The data were adjusted for the effects of significant non-genetic factors. Fertility traits like SP, PR and CR of Murrah buffaloes in each month of successful insemination were arranged along with the average THI of each month from January to December in each year and for 20 years, respectively.

\section{Threshold THI for fertility traits}

The effect of THI on fertility traits of Murrah buffaloes was assessed by using a fixed Least-squares model with software LSML[15]. The generated THI values were classified into eight Groups such as 45.00-49.99, 50.00-54.99, 55.00-59.99, 60.00-64.99, 65.00-69.99, 70.00-74.99, 80.00-84.99 and 85.0089.99 , respectively.

The model used was

$\mathrm{Y}_{\mathrm{ij}}=\mu+\mathrm{THI}_{\mathrm{i}}+\mathrm{e}_{\mathrm{ij}}$

Where, $Y_{i j}$ is the observed fertility trait of $j^{\text {th }}$ Murrah buffalo under $i^{\text {th }}$ THI subclasses, $\mu=$ overall mean, $\mathrm{THI}_{\mathrm{i}}=$ fixed effect of $\mathrm{i}^{\text {th }} \mathrm{THI}(1-8)$ and $\mathrm{e}_{\mathrm{ij}}$ is random error $\sim$ NID $\left(0, \sigma^{2}\right)$. Least-squares means along with standard errors for fertility traits under different THI subclasses were estimated. The significant effect of THI on fertility traits was assessed, and traits were adjusted with the significant effect of THI. The difference of means between THI sub-classes was tested using DMRT as modified by Kramer [16]. The threshold THI value for fertility traits was identified. Based on threshold THI value, two zones such as non-heat stress zone (NHSZ) and HSZ were determined in a year. Simple linear regression model was used to develop CHSZ within the HSZ. The regression model used was as follows.

$$
\mathrm{Y}_{\mathrm{ij}}=\mathrm{a}+\mathrm{b} \mathrm{x}_{\mathrm{i}}+\mathrm{e}_{\mathrm{ij}}
$$

Where, $a$ is intercept, $b$ is regression coefficient and $e_{i j}$ is random residual $\sim \operatorname{NID}\left(0, \sigma^{2} e\right)$. The zone where maximum increase in SP and decline in PR and CR were observed with per unit rise in monthly average THI was determined as the critical heat stress within the HSZ.
Genetic evaluation of fertility traits in non-heat stress, heat stress and critical HSZs

Murrah buffaloes were genetically evaluated in NHSZ, HSZ and CHSZ based on their EBV for SP, PR and CR. Paternal half-sib correlation method [17] was used to estimate $\left(\mathrm{h}^{2}\right)$ of different fertility traits. Similarly, (r) of each fertility trait was estimated by intra class correlation method [18]. The EBV for each fertility trait was estimated for buffaloes under each zone as follows.

$\mathrm{EBV}=\overline{\mathrm{H}}+\mathrm{nh}^{2}(\overline{\mathrm{X}}-\overline{\mathrm{H}}) / 1+(\mathrm{n}-1) \mathrm{r}$

Where, $\overline{\mathrm{H}}=$ Herd average of each fertility trait, $\mathrm{n}=$ number of records, $\mathrm{h}^{2}=$ heritability estimate of fertility trait, $r=$ repeatability estimate of fertility trait, $\overline{\mathrm{X}}=$ average of each fertility trait.

\section{Results}

The month wise average dry bulb temperature varied from $12.43^{\circ} \mathrm{C}$ in the month of January to $-32.54^{\circ} \mathrm{C}$ in may while $\mathrm{RH}$ ranged between $42.01 \%$ in April and $80.72 \%$ in August during the period. The lowest monthly average THI was 56.71 in January, and the highest mean THI was 81.60 in June over 20 years period as shown in Figure 1.

\section{Threshold THI for fertility traits}

The parity $(\mathrm{p}<0.01)$ and period of calving $(\mathrm{p}<0.05)$ had significant effect on SP, but THI had highly significant effect $(p<0.001)$ on all the fertility traits of Murrah buffaloes (Table-2) The least square means of SP, PR and CR are presented in Table- 3 . The overall least squares means for SP, PR and CR were 135.79 days, 0.38 and $68.80 \%$, respectively. A distinct relationship was found between changes in

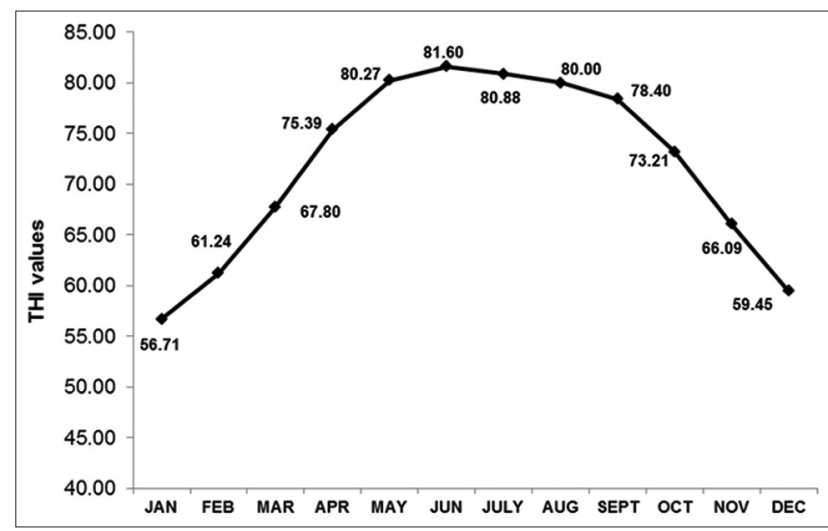

Figure-1: Monthly average temperature humidity index over 20 years (1993-2012) from January to December.

Table-1: Edited and normalized data structure of fertility traits of Murrah buffaloes.

\begin{tabular}{lcccc}
\hline Parity & Initial observations & Observations under SP & Observations under PR & Observations under CR \\
\hline $1^{\text {st }}$ & 581 & 477 & 417 & 464 \\
$2^{\text {nd }}$ & 409 & 355 & 273 & 350 \\
$3^{\text {rd }}$ & 244 & 222 & 157 & 216 \\
$4^{\text {th }}$ & 145 & 138 & 108 & 135 \\
Overall & 1379 & 1192 & 955 & 1165 \\
\hline
\end{tabular}

$\mathrm{SP}=$ Service period, $\mathrm{PR}=$ Pregnancy rate, $\mathrm{CR}=$ Conception rate 
fertility traits in relation to increasing in THI value. The average SP was estimated 127 days for THI subclass 70-74.99 that was increased to 162 days in THI subclass 75-79.99. The decrease in CR was evident from $76 \%$ in THI subclass $70-74.99$ to $67 \%$ at THI value higher than 75 . Similarly, PR was found declined from 0.41 to 0.25 in THI subclass 75-79.99 (Table-3). The negative effects of heat stress on fertility traits were observed above THI 75 which inferred that threshold THI value for SP, PR and CR were 75 in Murrah buffaloes.

In our study, monthly average THI value $<75$ were found for the months from October to March while mean monthly THI value $>75$ was observed during April to September over 20 years period. Accordingly, two zones in a year were identified such as NHSZ with average THI 56.71-73.21 and HSZ with average THI 75.39-81.60. May and June were thus identified as CHSZ with THI 80.27-81.60.

\section{Genetic evaluation of fertility traits under NHSZ, HSZ and CHSZ}

The $\left(\mathrm{h}^{2}\right)$ of SP, PR and $\mathrm{CR}$ was estimated as $0.06 \pm 0.03,0.024 \pm 0.01$ and $0.04 \pm 0.03$, while the (r) estimates for the above traits were $0.13 \pm 0.04$, $0.059 \pm 0.04$ and $0.08 \pm 0.04$, respectively (Table-4). Murrah buffaloes were genetically evaluated in relation to heat stress through assessing EB Vin each of the non-heat stress, heat stress and critical HSZ for all the fertility traits. The herd averages of SP, PR and CR over three different zones were estimated as 139 days, 0.36 and $68.92 \%$, respectively. There was a trend in an increase in EBV of SP, decline in PR and CR from NHSZ to critical HSZ along with a decrease in the number of buffaloes (Table-5). The EBV of SP was estimated as $138.57,139.62$ and 140.92 days in three subsequent zones. The EBV of SP was found around 2 days higher under CHSZ as compared to NHSZ. The EBV of PR of Murrah Buffaloes was estimated as 0.362 under NHSZ that was declined to 0.358 under HSZ and further declined to 0.357 under critical HSZ. EBV of PR was decreased by $0.5 \%$ in CHSZ than NHSZ. The EBV of CR was $69.02 \%, 68.81 \%$ and $68.71 \%$ under NHSZ, HSZ and CHSZ, respectively (Table-5). The EBV of CR in Murrah buffaloes was found $0.31 \%$ lower in CHSZ as compared to NHSZ.

\section{Discussion}

There are several factors responsible for poor reproductive performances of animals. The climate data in terms of THI indicated that the reproductive performance of Murrah buffaloes was highly affected due to heat stress in the months with high THI values. Upadhyay et al. [19] earlier reported THI value 75 in the month of February and found to be increased to 85 in May and 95 in the month of July and August in Karnal. A comparable mean SP in Murrah buffaloes was estimated as 161.65 days [20]. Patil et al. [12] obtained a similar result of 0.36 Daughter PR in the $1^{\text {st }}$ parity after considering VWP 63 in Murrah
Table-2: Analysis of variance (mean $\pm S D$ values) of fertility traits in Murrah buffaloes.

\begin{tabular}{lccc}
\hline $\begin{array}{l}\text { Source of } \\
\text { variation }\end{array}$ & SP (days) & PR & CR (\%) \\
\hline $\begin{array}{l}\text { Parity } \\
\text { Period of }\end{array}$ & $\begin{array}{c}50654.78(3) \\
\text { calving }\end{array}$ & $0.27(3)$ & $366.89(3)$ \\
$\begin{array}{l}\text { Age group at } \\
\text { first calving }\end{array}$ & $378.11(2)$ & $0.18(2)$ & $200.37(2)$ \\
THI & $68265.77(7)$ & $1.08(7)$ & $3525.74(7)$ \\
Error & $7063.25(1167)$ & $0.15(930)$ & $920.05(1140)$ \\
\hline
\end{tabular}

$\mathrm{SP}=$ Service period, $\mathrm{PR}=$ Pregnancy rate, $\mathrm{CR}=$ Conception rate, figures in parentheses indicate respective degree of freedom, $p<0.05, p<0.01, p<0.001$, THI=Temperature humidity index, SD=Standard deviation

Table-3: Least-squares means and standard errors of SP, $\mathrm{PR}$ and $\mathrm{CR}$ in Murrah buffaloes.

\begin{tabular}{cccc}
\hline THI effects & SP (days) & PR & CR (\%) \\
\hline Overall $(\mu)$ & $135.79 \pm 3.17$ & $0.38 \pm 0.02$ & $68.80 \pm 01.18$ \\
& $(1192)$ & $(955)$ & $(1165)$ \\
THI subclasses & & & \\
$45.00-49.99$ & $136.47^{\mathrm{f}} \pm 17.31$ & $0.31^{\mathrm{c}} \pm 0.08$ & $58.64^{\mathrm{a}} \pm 06.42$ \\
& $(23)$ & $(20)$ & $(22)$ \\
$50.00-54.99$ & $130.67^{\mathrm{d}} \pm 6.30$ & $0.40^{\mathrm{e}} \pm 0.03$ & $66.67^{\mathrm{c}} \pm 02.35$ \\
& $(166)$ & $(139)$ & $(164)$ \\
$55.00-59.99$ & $132.13^{\mathrm{e}} \pm 7.20$ & $0.44^{\mathrm{g}} \pm 0.04$ & $65.73^{\mathrm{b}} \pm 02.70$ \\
& $(127)$ & $(105)$ & $(124)$ \\
$60.00-64.99$ & $116.55^{\mathrm{b}} \pm 5.80$ & $0.53^{\mathrm{h}} \pm 0.03$ & $76.87^{\mathrm{h}} \pm 02.16$ \\
& $(196)$ & $(157)$ & $(194)$ \\
$65.00-69.99$ & $113.44^{\mathrm{a}} \pm 10.66$ & $0.39^{\mathrm{d}} \pm 0.06$ & $70.53^{\mathrm{f}} \pm 03.95$ \\
& $(58)$ & $(44)$ & $(58)$ \\
$70.00-74.99$ & $127.17^{\mathrm{c}} \pm 5.44$ & $0.41^{\mathrm{f}} \pm 0.03$ & $75.92^{\mathrm{g}} \pm 02.04$ \\
& $(223)$ & $(160)$ & $(217)$ \\
$75.00-79.99$ & $162.02^{\mathrm{g}} \pm 7.09$ & $0.25^{\mathrm{a}} \pm 0.04$ & $67.40^{\mathrm{d}} \pm 02.68$ \\
& $(131)$ & $(107)$ & $(126)$ \\
$80.00-84.99$ & $167.84^{\mathrm{h}} \pm 4.96$ & $0.30^{\mathrm{b}} \pm 0.03$ & $68.63^{\mathrm{e}} \pm 01.87$ \\
& $(268)$ & $(223)$ & $(260)$ \\
\hline
\end{tabular}

$\mathrm{p}<0.001$; Means with dissimilar superscripts indicate a significant difference between THI sub-classes; Figures in parenthesis are a number of observations, $\mathrm{THI}=$ Temperature humidity index

Table-4: Genetic parameters (heritability and repeatability estimates) of fertility traits of Murrah buffaloes.

\begin{tabular}{lcc}
\hline Traits & Heritability $\left(\mathbf{h}^{2}\right)$ & Repeatability $(\mathbf{r})$ \\
\hline SP (days) & $0.06 \pm 0.03(986)$ & $0.13 \pm 0.04(975)$ \\
PR & $0.024 \pm 0.01(782)$ & $0.059 \pm 0.04(755)$ \\
CR (\%) & $0.04 \pm 0.03(964)$ & $0.08 \pm 0.04(957)$ \\
\hline
\end{tabular}

$\mathrm{SP}=$ Service period, $\mathrm{PR}=$ Pregnancy rate, $\mathrm{CR}=$ Conception rate, Figures in parenthesis are number of observations

buffaloes. The least square mean for CR was in confirmation of the findings of Nawale [21].

In this study, THI should be $<75$ for optimum reproductive performances of Murrah buffaloes and decline in fertility was observed with an increase in THI above 75. Ingraham et al. [22] indicated the decline in CR of Holstein cows from $55 \%$ to $10 \%$ with an increase in average THI of the day of service from 70 to 84 . There is significant $(\mathrm{p}<0.05)$ decrease in the first service PR with increase in THI above 72 which corresponds to $25^{\circ} \mathrm{C}$ and RH 50\% [23]. Hisashi 
Table-5: EBV for fertility traits of Murrah buffaloes in different zones.

\begin{tabular}{lcccc}
\hline Zones & $\begin{array}{c}\text { Average } \\
\text { THI value }\end{array}$ & $\begin{array}{c}\text { EBV for service } \\
\text { period (days) }\end{array}$ & $\begin{array}{c}\text { EBV for } \\
\text { pregnancy rate }\end{array}$ & $\begin{array}{c}\text { EBV for conception } \\
\text { rate (\%) }\end{array}$ \\
\hline NHSZ (October-March) & $56.71-73.21$ & $138.57(427)$ & $0.362(396)$ & $69.02(415)$ \\
HSZ (April-September) & $75.39-81.60$ & $139.62(313)$ & $0.358(261)$ & $68.81(311)$ \\
CHSZ (May, June) & $80.27-81.60$ & $140.92(86)$ & $0.357(78)$ & $68.71(157)$ \\
\hline
\end{tabular}

$\mathrm{NHSZ}=$ Non heat stress zone, HSZ=Heat stress zone, CHSZ=Critical heat stress zone, Figures in parenthesis are a number of observations, EBV $=$ Expected breeding values

et al. [7] identified the negative association of CR of lactating dairy cows with increase in THI in south western Japan at THI values higher than 80 .

Our findings classified a whole year into three different zones viz.; NHSZ including months from October to March with mean THI 56.71-73.21, HSZ from April to September with mean THI 75.39-81.60 and CHSZ in the months of May and June with mean THI 80.27-81.60. The THI values are classified into three different classes of THI as comfortable $(\leq 70)$, stressful (71-78) and extreme distress (>78)[24]. Armstrong [25] categorized THI values into five different classes as no stress with THI value $<72$, mild stress (72-78), moderate stress (79-88), severe stress (89-98) and dead cows with THI $>98$.

The $\left(\mathrm{h}^{2}\right)$ and $(\mathrm{r})$ estimates of SP in Murrah buffaloes were 0.06 and 0.13 in the present study. Thiruvenkadan et al. [26] reported a lower estimate of $\left(\mathrm{h}^{2}\right)$ of SP in Murrah buffalo cows. The variation may be due to the difference in number of sires used for breeding, differences in management practices and environmental conditions such as ambient temperature, humidity and rainfall. Jamuna [27] obtained a comparable estimate for (r) of SP $(0.15 \pm 0.05)$ in Murrah buffaloes. She has also estimated the $\left(\mathrm{h}^{2}\right)$ and (r) of PR in Murrah buffaloes as 0.02 and $0.09 \pm 0.05$, which are in agreement with our findings. Boichard and Manfredi [28] reported the $\left(\mathrm{h}^{2}\right)$ and (r) estimates of CR of French Holstein dairy cattle as 0.02 and 0.032 .

The EBV for SP was found increased from NHSZ to CHSZ, while the decline in EBV for PR and CR was observed from NHSZ to CHSZ in Murrah buffaloes. There was no report available regarding the estimation of breeding values for fertility traits of Murrah buffaloes in three different zones in a year under subtropical climate. The breeding value of $\mathrm{CR}$ and $\mathrm{PR}$ of Angus heifer cattle ranged between -0.2582 to 0.3401 and -0.4821 to 0.7793 [29]. Bermann et al. [10] also reported breeding value for PR of sires of Angus heifer cattle as $-0.02-0.05$.

\section{Conclusion}

The result revealed that May and June months were the CHSZ for SP and PR, The months June, July and August months were the CHSZ for CR in Murrah buffaloes. The breeding value for fertility traits was influenced by THI. The EBV for fertility traits differed in three zones. In CHSZ the EBV of SP was found around 2 days higher than NHSZ. A decline of $-0.5 \%$ in EBV of PR and $-0.31 \%$ in the EBV of $\mathrm{CR}$ was observed in CHSZ as compared to NHSZ. As an overall conclusion, climatic factors seem to influence on fertility and in order to enhance the fertility performance of Murrah buffaloes proper management should be followed during the CHSZ.

\section{Authors' Contributions}

AKC designed the work. SD conducted study and analyzed the data. PRS and AU helped in the compilation of data. AKC and AS reviewed and edited the manuscript. VS and KMS helped in writing the manuscript. All authors read and approved the final manuscript.

\section{Acknowledgements}

The authors are thankful to the Director, NDRI for providing necessary infrastructure and facilities for the successful completion of research work. Special thanks to Indian Council of Agricultural Research (ICAR), Ministry of Agriculture, Govt. of India for proving Junior Research Fellowship to the first author for conducting the study.

\section{Competing Interests} interest.

The authors declare that they have no competing

\section{References}

1. BAHS, Basic Animal Husbandry Statistics. (2012) Department of Animal Husbandry, Dairying and Fisheries, Ministry of Agriculture, Government of India.

2. $1^{\text {th }}$ Livestock Census (2012) Department of Animal Husbandry, Dairying \& Fisheries, Ministry of Agriculture, Government of India.

3. Buffington, D., Collazo-Arochu, A., Canton, H.H., Pritt, D., Thatcher, W.W. and Collier, R.J. (1981) Black globe-humidity index (BGHI) as comfort equation for cows. Trans. Am. Soc. Agric. Eng., 34: 711.

4. Das, G.K. and Khan, F.A. (2010) Summer anoestrus in buffalo - A review. Reprod. Domest. Anim., 45: 483-494.

5. Singh, M., Chaudhari, B.K., Singh, J.K., Singh, A.K. and Maurya, P.K. (2013) Effects of thermal load on Buffalo reproductive performance during summer season. J. Biol. Sci., 1(1): 1-8.

6. Marai, I.F.M. and Habeeb, A.A.M. (2010) Buffalo's biological functions as affected by heat stress - A review. Livest. Sci., 127: 89-109.

7. Hisashi, N., Hiroshi, O., Toshihumi, N., Tetsuo, M., Koji, A. and Yasuhiro, T. (2011) Effect of the temperature humidity index on body temperature and conception rate of lactating dairy cows in South Western Japan. J. Reprod. Dev., 57: 450-456. 
8. Ravagnolo, O. and Misztal, I. (2002) Effect of heat stress on non return rate in Holstein cows: Fixed model analyses. $J$. Dairy Sci., 85: 3101-3106.

9. Kumar, V. and Chakravarty, A.K. (2014) Breeding value estimation on selection trait of Murrah buffalo. Int. J. Curr. Res., 6: 8132-8134.

10. Bormann, J.M., Totir, L.R., Kachman, S.D., Fernando, R.L. and Wilson, D.E. (2006) Pregnancy rate and first-service conception rate in Angus heifers. J. Anim. Sci., 84: 2022-2025.

11. Van Raden, P.M., Sandres, A.H., Tooker, M.E., Miller, R.H., Norman, H.D., Kuhn, M.T. and Wiggan, G.R. (2004) Development of a National genetic evaluation for cow fertility. J. Dairy Sci., 87: 2285-2292.

12. Patil, C.S., Chakravarty, A.K., Singh, A., Kumar, V., Jamuna, V. and Vohra, V. (2014) Development of a predictive model for daughter pregnancy rate and standardization of voluntary waiting period in Murrah buffalo. Trop. Anim. Health Prod., 46: 279-284.

13. Jensen, M.E., Burman, R.D. and Allen, R.G. (1990) Evapotranspiration and irrigation water requirements. American Society of Civil Engineers-Manuals and Reports on Engineering Practice No. 70. p332.

14. Yousef, M.K. (1985) Stress Physiology in Livestock. CRC Press, Boca Raton, Florida, USA.

15. Harvey, W.R. (1990) User's Guide for LSMLMW. PC-2 Version, Mixed Model Least Squares and Maximum Likelihood Computer Programme, Mimeograph. Ohio State University Press, Columbus, USA.

16. Kramer, C.Y. (1957) Extension of multiple range tests to group correlated adjusted means. Biometrics, 13: 13-18.

17. Becker, W.A. (1975) Manual of Quantitative Genetics. $3^{\text {rd }}$ ed. Washington State University, Washington, USA.

18. Falconer, D.S. and Mackay, T.F.C. (1996) Introduction to Quantitative Genetics. $4^{\text {th }}$ ed. Longman Group Ltd., Essex, England.

19. Upadhyay, R.C., Ashutosh, Rani, R., Singh, S.V., Mohanty, T.K. and Gohain, M. (2012) Impact of climate change on reproductive functions of Murrah buffaloes. J. Anim. Plant Sci., 22(3): 234-236.

20. Patil, C.S., Chakravarty, A.K., Kumar V., Dongre, V.B. and Kumar, P. (2011) Non-genetic factors affecting first lactation reproductive traits in Murrah buffaloes. Indian J. Anim. Res., 45(3): 205-207.

21. Nawale, V.S. (2010) Development of optimum model for prediction and assessment of breeding efficiency in Murrah buffaloes, Unpublished MVSc Thesis, NDRI, Karnal, Haryana, India.

22. Ingraham, R.H., Gillette, D.D. and Wagner, W.C. (1971) Relationship of temperature and humidity to conception rate in Holstein cows in a subtropical climate. J. Dairy Sci., 57: 476-481.

23. McGowan, M.R., Mayer, D.G., Tranter, W., Shaw, M., Smith, C. and Davison, T.M. (1996) Relationship between temperature humidity index and conception efficiency of dairy cattle in Queensland. Proc. Aust. Soc. Anim. Prod., 21: 454 .

24. McDowell, R.E., Hooven, N.W. and Camoens, J.K. (1976) Effects of climate on performance of Holsteins in first lactation. J. Dairy Sci., 59: 965-973.

25. Armstrong, D.V. (1994) Heat stress interactions with shade and cooling. J. Dairy Sci., 77: 2044-2050.

26. Thiruvenkadan, A.K., Panneerselvam, S., Rajendran, R. and Murali, N. (2010) Analysis on the productive and reproductive traits of Murrah buffalo cows maintained in the coastal region of India. Appl. Anim. Husbandry Rural Dev., 2010(3): 1-5

27. Jamuna, V. (2012) Impact of progeny testing programme on life time fertility and life time milk yield in Murrah buffaloes, Unpublished MVSc Thesis, NDRI, Karnal, Haryana, India.

28. Boichard, D. and Manfredi, E. (1994) Genetic analysis of conception rate in French Holstein cattle. Acta Agric. Scand. Sect. A Anim. Sci., 44: 138-145.

29. Minick, J.A., Totir, L.R., Wilson, D.E. and Fernando, R.L. (2004) Pregnancy Rate in Angus Heifers. Animal Industry Report, AS 650, ASL R1878. 